$03,05,11$

\title{
Влияние высокого давления на электрические и гальваномагнитные свойства композита $\mathrm{Cd}_{3} \mathrm{As}_{2}-20 \mathrm{~mol}$. \% MnAs
}

\author{
(c) Л.А. Сайпулаева ${ }^{1}$, М.М. Гаджиалиев ${ }^{1}$, А.Г. Алибеков ${ }^{1}$, Н.В. Мельникова ${ }^{2}$, В.С. Захвалинский ${ }^{3}$, \\ А.И. Риль ${ }^{4}$, С.Ф. Маренкин ${ }^{4}$, А.Н. Бабушкин ${ }^{2}$ \\ ${ }^{1}$ Институт фризики им. Х.И. Амирханова ДФИЦ РАН, \\ Махачкала, Россия \\ ${ }^{2}$ Уральский фредеральный университет, Институт естественных наук и математики, \\ Екатеринбург, Россия \\ ${ }^{3}$ Белгородский государственный национальный исследовательский университет, \\ Белгород, Россия \\ ${ }^{4}$ Институт общей и неорганической химии им. Н.С. Курнакова РАН, \\ Москва, Россия \\ E-mail: luizasa11@mail.ru
}

Поступила в Редакцию 30 декабря 2019 г.

В окончательной редакции 30 декабря 2019 г.

Принята к публикации 10 января 2020 г.

\begin{abstract}
Представлены результаты исследования барических зависимостей удельного электросопротивления, коэффициента Холла, подвижности носителей заряда, магнетосопротивления композита $\mathrm{Cd}_{3} \mathrm{As}_{2}+20$ mol.\% $\mathrm{MnAs}$ в области давлений до $9 \mathrm{GPa}$. На барических зависимостях всех исследованных характеристик обнаружены особенности, связанные с фазовыми переходами. Установлено наличие индуцированного давлением отрицательного магнетосопротивления.
\end{abstract}

Ключевые слова: высокое давление, эффект Холла, удельное электросопротивление, отрицательное магнетосопротивление, структурный фазовый переход.

DOI: $10.21883 /$ FTT.2020.06.49333.32M

\section{1. ВВедение}

Соединение $\mathrm{Cd}_{3} \mathrm{As}_{2}$ относится к особому классу топологических изоляторов - дираковским полуметаллам и является трехмерным аналогом графена [1]. В таких материалах носителями заряда являются дираковские фермионы, которые имеют нулевую эффективную массу и подчиняются релятивистским законам движения. Материал характеризуется необычайно высокой подвижностью электронов, значительно превышающей $10^{4} \mathrm{~cm}^{2} /(\mathrm{Vs})$ при комнатной температуре и $10^{6} \mathrm{~cm}^{2} /(\mathrm{Vs})$ при низких температурах [1]. $\mathrm{Cd}_{3} \mathrm{As}_{2}$ привлек внимания исследователей проявлением интересных свойств (нетривиальная зонная структура, высокоподвижные электроны) и перспективой применения в разных областях техники. Для манипулирования спиновым ансамблем высокоподвижных носителей заряда в $\mathrm{Cd}_{3} \mathrm{As}_{2}$ необходимо создать топологические изоляторы с управляемым внедрением в кристаллическую решетку атомов, имеющих собственный нескомпенсированный магнитный момент (Fe, Mn, V, Cr, Co). Если выбрать $\mathrm{Cd}_{3} \mathrm{As}_{2}$ в качестве дираковского полуметалла, то для уменьшения образования при синтезе дополнительных фаз требуется выбирать ферромагнитный материал из соединений типа магнитный атом - As. Наиболее известной в настоящее время считается система $\mathrm{Mn}-\mathrm{As}$. Для этой системы при низких значениях количества Mn (менее 50\% mol.) стабильных химических соединений не обнаружено. Поэтому при синтезе композитов
$\mathrm{Cd}_{3} \mathrm{As}_{2}+\mathrm{MnAs}$ использована система $\mathrm{Mn}-\mathrm{As}$, где содержание атомов Mn выше 50\% mol. [2].

Марганец растворяется в $\mathrm{Cd}_{3} \mathrm{As}_{2}$ образуя широкую область тройных твердых растворов $\left(\mathrm{Cd}_{1-x} \mathrm{Mn}_{x}\right) 3 \mathrm{As}_{2}$. Превышение содержания марганца приводит к образованию композита на основе $\mathrm{Cd}_{3} \mathrm{As}_{2}$, содержащего наряду с твердым раствором $\left(\mathrm{Cd}_{1-x} \mathrm{Mn}_{x}\right)_{3} \mathrm{As}_{2}$, включения MnAs [2]. В настоящее время физические свойства композитов $\mathrm{Cd}_{3} \mathrm{As}_{2}+\mathrm{MnAs}$ до конца не изучены.

Цель настоящей работы - изучение влияния давления, температуры и магнитного поля на электрические и гальваномагнитные свойства (эффекта Холла и магнитосопротивления) композита $\mathrm{Cd}_{3} \mathrm{As}_{2}+20$ mol.\% MnAs.

Опираясь на поставленную цель, необходимо было решить следующие задачи: исследовать влияние гидростатического давления до $9 \mathrm{GPa}$ в магнитном поле до $5 \mathrm{kOe}$ на поведение таких характеристик, как электросопротивление, магнетосопротивление, коэффициент Холла, подвижность носителей заряда, а также изучить температурные зависимости электрических параметров в диапазоне температур 77-450 K.

\section{2. Методика исследований и экспериментальное оборудование}

Объемные образцы $\mathrm{Cd}_{3} \mathrm{As}_{2}-\mathrm{MnAs}$ получены в Институте общей и неорганической химии им. Н.С. Курнакова РАН [2]. Синтез сплава проводили вакуумно- 


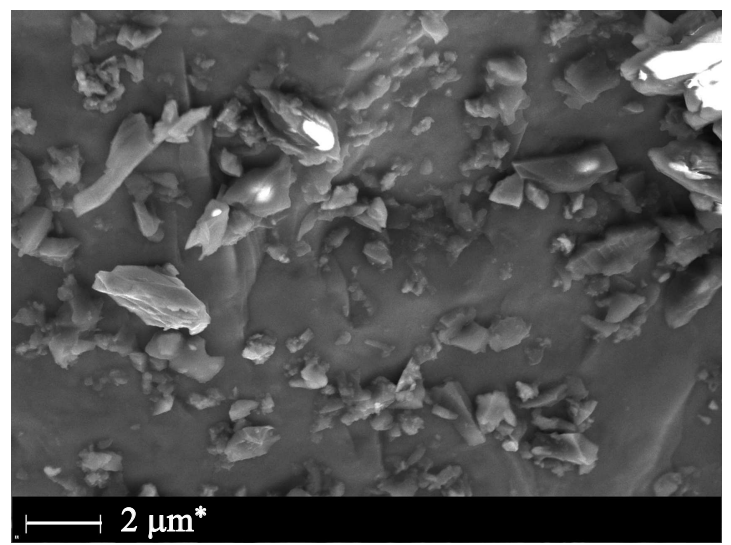

Рис. 1. СЭМ-изображение поверхности образца $\mathrm{Cd}_{3} \mathrm{As}_{2}+20$ mol.\% MnAs

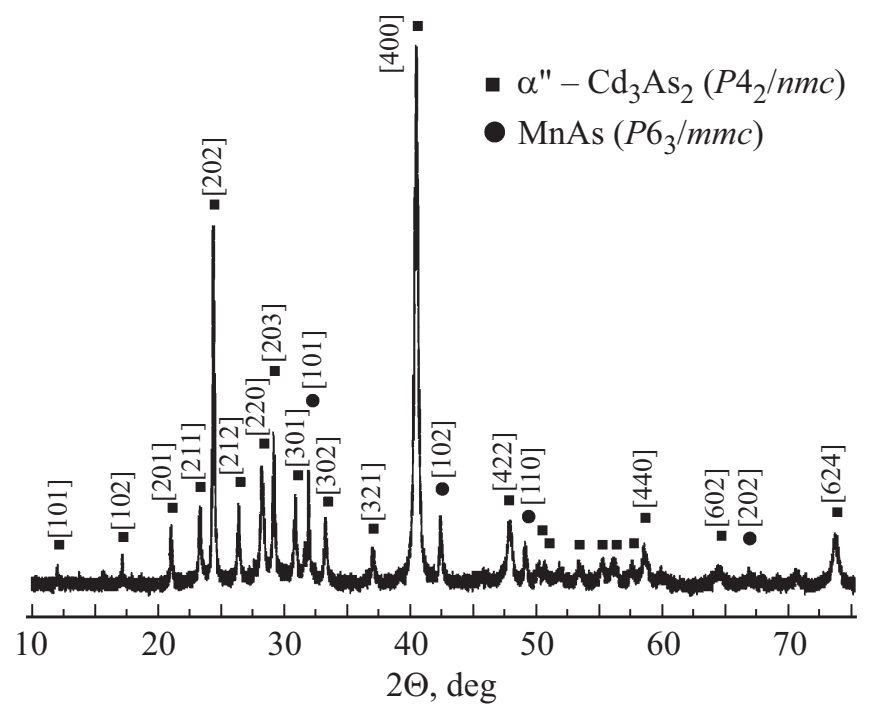

Рис. 2. Рентгенограмма образца.

ампульным методом из соединений $\mathrm{Cd}_{3} \mathrm{As}_{2}$ и $\mathrm{MnAs}$ при температуре плавления арсенида марганца. Структура образцов, их состав и распределение элементов на поверхности изучались с помощью сканирующего электронного микроскопа JSM-6610LV (Jeol) с приставкой для энергодисперсионной рентгеновской спектроскопии (ЭДРС) X-MaxN (Oxford Instruments).

Электронно-микроскопическое исследование скола $\mathrm{Cd}_{3} \mathrm{As}_{2}+20$ mass.\% MnAs показало (рис. 1), что исследуемый материал не является монокристаллом - он состоит из крупных блоков.

Идентификацию образца производили с помощью порошковой дирактометрии (РФА) в Центре коллективного пользования ИОНХ РАН на дифрактометре BRUKER D8 ADVANCE (излучение $\mathrm{Cu} K_{\alpha}$, шаг съемки $0.014^{\circ}$, выдержка $1.3 \mathrm{~s}$, база порошковых дифрактометрических данных ICDD PDF-2, программа Diffrac.SuiteEVA) и оригинальной установке дифференциально термического анализа (ДТА) в ИОНХ РАН.
При расшифровке дифракционных картин установлено, что рентгенограммы (рис. 2) содержали две основные фазы - тетрагональную $\mathrm{Cd}_{3} \mathrm{As}_{2}$ и гексогональную (ферромагнитную) MnAs. Кроме того, было отмечено наличие незначительного количества фазы $\mathrm{CdAs}_{2}$.

Для создания высокого давления использовалась камера типа „Тороид“ создающая высокое гидростатическое давление до $9 \mathrm{GPa}[3,4]$. Образцы представляли собой прямоугольные параллелепипеды с размерами $3 \times 1.0 \times 1.0 \mathrm{~mm}$.

Исследование эффекта Холла $R_{H}$ проводилось методом постоянного тока $I$ и постоянного магнитного поля $H$. Значение $R_{H}$ определяется концентрацией и подвижностью электронов и дырок в веществе. Когда носителями тока являются только свободные электроны, $R_{H}=1 / n \cdot e$, где: $n-$ концентрация электронов; $e-$ заряд электрона.

\section{3. Результаты и их обсуждения}

Электрические свойства изучаемых структур зависят от размеров гранул, от плотности их упаковки. Если средняя плотность частиц мала, то проводимость такой среды будет весьма низкой. При большой плотности, когда значительное число частиц соприкасаются друг с другом, в структуре могут образоваться достаточно протяженные кластеры, и проводимость такой структуры будет иметь более сложный характер, чем в случае применимости правила аддитивности. Реальная проводимость композита будет определяться как проводимостью фаз $\mathrm{MnAs}, \mathrm{Cd}_{3} \mathrm{As}_{2}$, переходного слоя между ними и формой гранул. Вероятность туннелирования носителей заряда определяется размерами и расстоянием между гранулами, высотой, шириной и формой туннельных барьеров, температурой среды.

На рис. 3 приведена температурная зависимость удельного сопротивления $\rho(T)$ композита $\mathrm{Cd}_{3} \mathrm{As}_{2}$ с

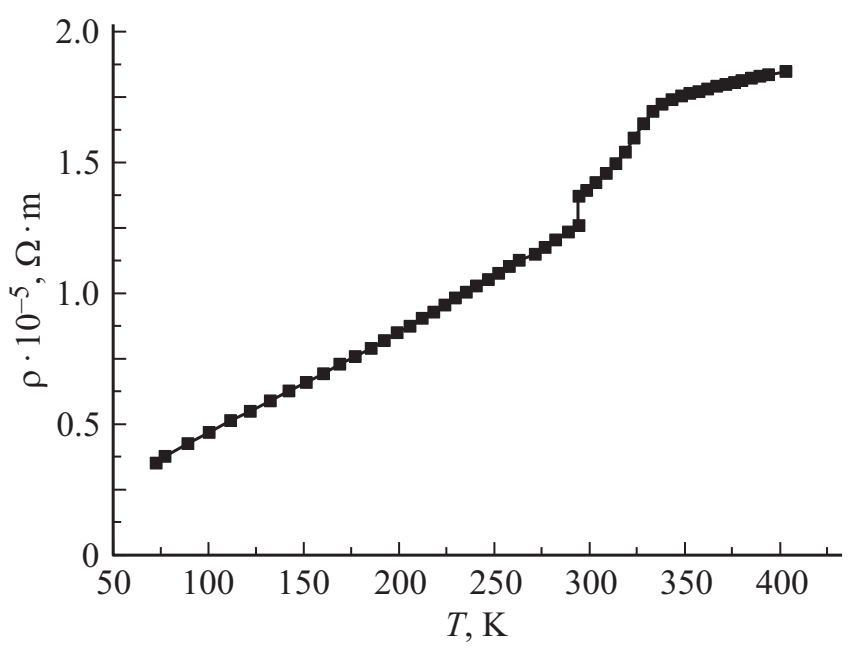

Рис. 3. Температурная зависимость удельного электросопротивления. 

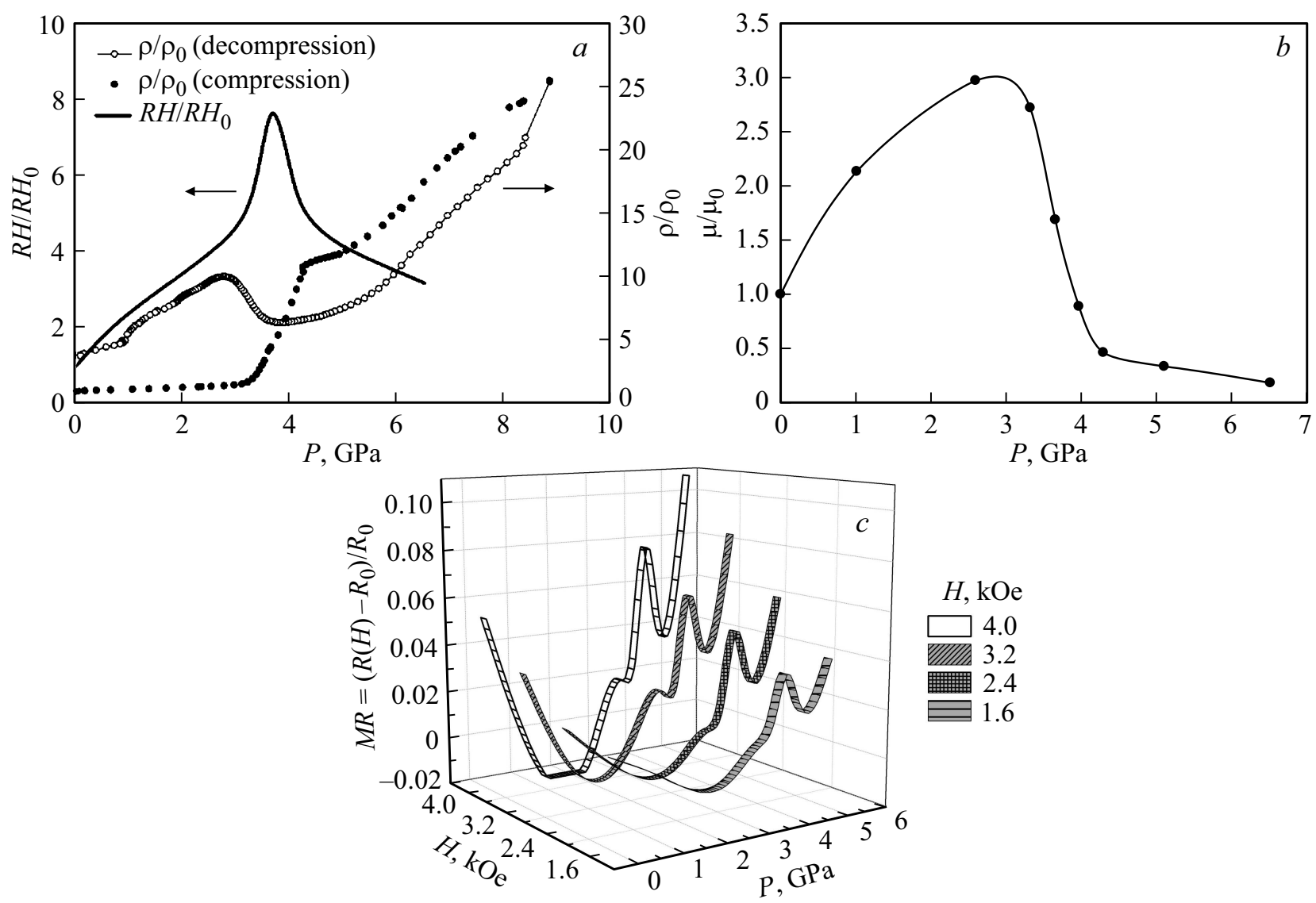

Рис. 4. Барические зависимости: a) удельного электросопротивления (при подъеме и сбросе) и коэффициента Холла, $b)$ подвижностей носителей заряда, $c$ ) магнетосопротивления при фиксированных значениях магнитного поля.

20 mol.\% MnAs в диапазоне температур 77-450 K. В исследованном диапазоне температур для композита характерен металлический тип проводимости. В интервале температур 300-330 K наблюдается скачок сопротивления (рис. 3), который обусловлен изменением механизма рассеяния электронов проводимости на границе между немагнитными и, в этом диапазоне температур, уже не ферромагнитными, а парамагнитными областями $\mathrm{MnAs}$ в композите (для MnAs температура Кюри составляет $\sim 31 \mathrm{~K}[5])$.

Барические зависимости удельного электросопротивления (при подъеме и сбросе), коэффициента Холла, а также магнетосопротивления при фиксированных значениях магнитного поля, представлены на рис. 4. $\mathrm{C}$ ростом давления (см. рис. $4, a$ ) до $2.8 \mathrm{GPa}$ удельное электросопротивление очень медленно монотонно растет, затем наблюдается резкий его рост, скорость этого роста (производная $\frac{\partial \rho}{\partial P}$ ) достигает своего максимума при $P=4.2 \mathrm{GPa}$, затем сопротивление продолжает монотонно расти с меньшей скоростью. При сбросе давления удельное электросопротивление ведет себя немонотонно, падает с различными барическими коэффициентами, и при $P=2.75 \mathrm{GPa}$ наблюдается максимум удельного электросопротивления. Барические зависимости электросопротивления в области давлений от 15 до $50 \mathrm{GPa}$ представлены в [6].
Если предположить, что при атмосферном давлении электрические и магнитные свойства в основном определяются поведением нанокластеров MnAs, как и в случае композита $\mathrm{Cd}_{3} \mathrm{As}_{2}+\mathrm{MnAs}$ (52.7 at.\% MnAs) [6], то в условиях высоких давлений значительную роль также могут играть и изменение расстояний между гранулами, и возможные проявления особенностей структурных характеристик и свойств матрицы композита.

Коэффициент Холла $\left(R_{H}\right)$ проходит через максимум при давлении $P \approx 3.65 \mathrm{GPa}$. Его поведение коррелирует с барической зависимостью $\rho(P)$.

На рис. 4, $b$ представлены барические зависимости холловской подвижности носителей заряда для $\mathrm{Cd}_{3} \mathrm{As}_{2}+20$ mol.\% MnAs. Наиболее быстрое снижение подвижности наблюдается при увеличении давления в интервале от 3.3 до $4.2 \mathrm{GPa}$.

На барических зависимостях магнетосопротивления (рис. 4,c) обнаружено проявление отрицательного магнитосопротивления (ОМС), максимальное значение которого (около 1\%) наблюдается в интервале давлений $1-2.6 \mathrm{GPa}$. Кроме наличия ОМС в исследуемом материале ярко проявляются особенности поведения положительного магнитосопротивления (рис. 4,c): величина пика на барических зависимостях магнетосопротивления, наблюдаемого в окрестности $4 \mathrm{GPa}$, растет с увеличением напряженности магнитного поля. Для уточ- 


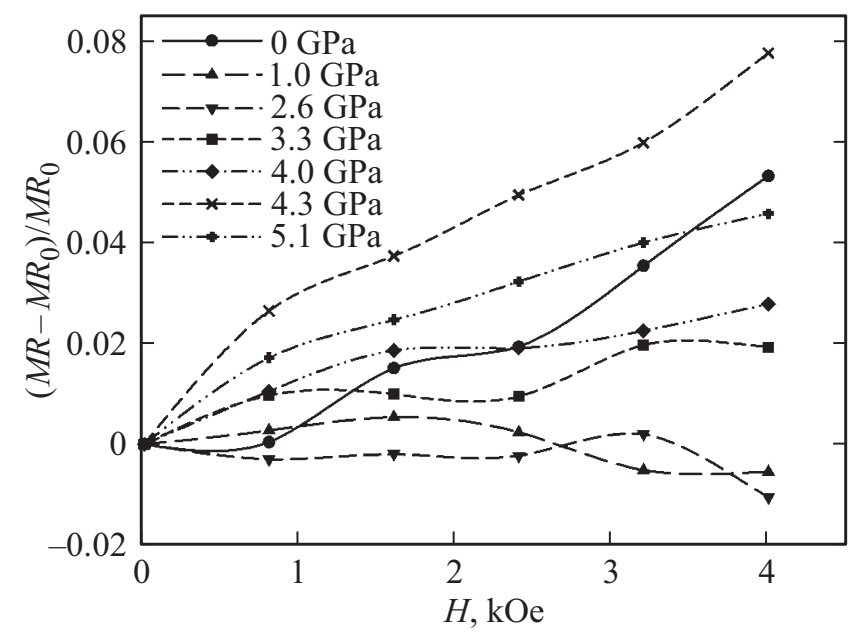

Рис. 5. Полевые зависимости магнетосопротивления при фиксированных значениях давления.

нения условий проявления ОМС исследовали полевые зависимости магнетосопротивления при фиксированных значениях давления (рис. 5).

Таким образом, на барических зависимостях удельного электросопротивления, коэффициента Холла, подвижностей носителей заряда и магнитосопротивления в области давлений 3-4 GPa обнаружены особенности поведения, которые связаны с фазовым переходом, соответствующим фазовым переходам в полупроводниковой матрице композита $\mathrm{Cd}_{3} \mathrm{As}_{2}$ и в ферромагнитных гранулах MnAs. Можно предположить, что в сплаве $\mathrm{Cd}_{3} \mathrm{As}_{2}-20 \mathrm{~mol} \% \mathrm{MnAs}$ под воздействием высокого давления, имеет место совмещение фазовых переходов структурного фазового перехода в матрице $\mathrm{Cd}_{3} \mathrm{As}_{2}$.

В интервале $2.6-4.0 \mathrm{GPa}$ происходит переход из тетрагональной к моноклинной структуре, что подтверждает данные [7]. В работе [8] методом нейтронной дифракции исследована атомная и магнитная структура MnAs при давлениях до 38 bar в диапазоне температур $15-300 \mathrm{~K}$ и установлено, что с понижением температуры при высоких давлениях в MnAs происходит спин-переориентационный переход из орторомбической фазы в новую фазу, имеющую как ферромагнитную, так и антиферромагнитую составляющую магнитного момента.

Причины проявления ОМС в полупроводниках и модели механизмов возникновения ОМС в гранулированных структурах, в частности, в композитах $\mathrm{Cd}_{3} \mathrm{As}_{2}+\mathrm{MnAs}$, обсуждались и представлены в ряде работ [9-13].

В условиях высоких давлений уменьшаются расстояния между гранулами MnAs, и изменяются особенности структурных характеристик и свойства матрицы $\mathrm{Cd}_{3} \mathrm{As}_{2}$. В гранулированных структурах транспортные свойства определяются не только процессами переноса зарядов в гранулах, но и туннелированием носителей между гранулами. Если размеры гранул и магнитных доменов сопоставимы между собой, то в магнитном поле магнитные моменты гранул выстраиваются параллельно, вдоль поля, и это приводит к меньшему рассеянию электронов проводимости и к проявлению ОМС. Туннельное сопротивление уменьшается с ростом внешнего магнитного поля по мере того, как оно упорядочивает намагниченность отдельных доменов. С ростом давления туннельное сопротивление уменьшается благодаря уменьшению расстояний между гранулами, т.е. благодаря уменьшениютуннелирующего барьера. Кроме того, необходимо учитывать наличие в самой матрице композита электрически активных дефектов, возникших в процессе синтеза композитных материалов и образования гранул MnAs, которые могут поставлять дырки или электроны. Часть дефектов представляют собой некомпенсированные атомы с ненулевым спином, которые играют роль локализованных магнитных моментов или магнитных центров рассеяния носителей в магнитном поле.

Если предположить, что размеры ферромагнитных гранул в $\mathrm{Cd}_{3} \mathrm{As}_{2}-20 \mathrm{~mol} \%$ MnAs значительно меньше (их не удалось наблюдать с использованием сканирующей электронной микроскопии), чем в $\mathrm{Cd}_{3} \mathrm{As}_{2}-44.7$ mol.\% MnAs [14], то можно ожидать, что на воздействие магнитного поля такой ансамбль наноразмерных ферромагнитных областей отреагирует при более низких давлениях Общая площадь поверхностей наногранул, через которые обеспечивается поставление части электронов проводимости в матрицу $\mathrm{Cd}_{3} \mathrm{As}_{2}$, в этом случае возрастет, и в условиях увеличения давления, когда матрица испытывает деформацию, уменьшается ее электросопротивление и расстояние между наногранулами уменьшается, при приложении магнитного поля магнитные моменты наногранул выстраиваются вдоль поля при относительно еще невысоких давлениях.

\section{4. Выводы}

Исследовано влияние высокого давления на электрические и гальваномагнитные свойства композита $\mathrm{Cd}_{3} \mathrm{As}_{2}-20$ mol.\% MnAs. На барических зависимостях удельного электросопротивления, коэффициента Холла, подвижностей носителей заряда и магнитосопротивления в области давлений 3-4 GPa обнаружены особенности поведения, которые связаны с фазовым переходом, соответствующим фазовым переходам в полупроводниковой матрице композита $\mathrm{Cd}_{3} \mathrm{As}_{2}$ и в ферромагнитных гранулах MnAs. На барических зависимостях магнетосопротивления обнаружено ОМС, максимальное значение которого (около 1\%) наблюдается в интервале давлений $1-2.6 \mathrm{GPa}$. Кроме наличия ОМС в исследуемом материале ярко проявляются особенности поведения положительного магнитосопротивления: величина пика на барических зависимостях магнетосопротивления, наблюдаемого в окрестности $4 \mathrm{GPa}$, растет с увеличением напряженности магнитного поля

\section{Конфликт интересов}

Авторы заявляют, что у них нет конфликта интересов. 


\section{Список литературы}

[1] T. Liang, Q. Gibson, M.N. Ali, M. Liu, R.J. Cava, N.P. Ong. Nature Mater. 14, 280 (2015).

[2] А.И. Риль, А.В. Кочура, С.Ф. Маренкин. А.Е. Кукзько, Б.А. Аронзон. Изв. Юго-Западного гос. ун-та. Сер. Техника и технологии 7 2(23), 120 (2017).

[3] L.G. Khvostantsev, L.P. Vereshchagin, A.P. Novikov. High Temp.-High Pressure, 9 6, 637 (1977).

[4] А.Ю. Моллаев, Л.А. Сайпулаева, Р.К. Арсланов, С.Ф. Маренкин. Неорган. материалы 37, 4, 405 (2001).

[5] Н.П. Гражданкина. УФН 96, 2, 291 (1968).

[6] N.V. Melnikova, A.V. Tebenkov, G.V. Sukhanova, A.N. Babushkin, L.A. Saipulaeva, V.S. Zakhavalinskii, S.F. Gabibov, A.G. Alibekov, A.Yu. Mollaev.. Solid State Phys. 60, 3. 499 (2018).

[7] L. He, Y. Jia, S. Zhang, X. Hong, C. Jin, S. Li. npj Quantum Mater. 1, 16014 (2016).

[8] В.П. Глазков, Д.П. Козленко, К.М. Подурец, Б.Н. Савенко, В.А. Соменков. Кристаллография 48, 1, 59 (2003).

[9] И.В. Бондарь, С.В. Труханов, Т.Г. Баругу. ФТП 49, 1320 (2015).

[10] Ю.В. Кабиров, В.Г. Гавриляченко, А.С. Богатин, Н.В. Лянгузов, Т.В. Гавриляченко, А.А. Кленушкин. ФТТ 58, 1263 (2016).

[11] С.Ф. Маренкин, А.Д. Изотов, И.В. Федорченко. ЖНХ 60 , 343 (2015).

[12] X.L. Wang, Q. Shao, A. Zhuravlyova. Sci. Rep. 5, 9221 (2015).

[13] A.G. Alibekov, A.Yu. Mollaev, L.A. Saipullaeva, S.F. Marenkin, I.V. Fedorchenko. Inorganic Mater. 52, 4, 357 (2016).

[14] Л.А. Сайпулаева, Ш.Б. Абдулвагидов, М.М. Гаджиалиев, А.Г. Алибеков, Н.В. Мельникова, Е.А. Степанова, Д.О. Аликин, В.С. Захвалинский, А.И. Риль, С.Ф. Маренкин, 3.Ш. Пирмагомедов. Физика и техника высоких давлений 29, 4, 48 (2019).

Редактор Т.Н. Василевская 